\title{
Tactile Defensiveness and Impaired Adaptation of Neuronal Activity in the Fmr1 Knock-Out Mouse Model of Autism
}

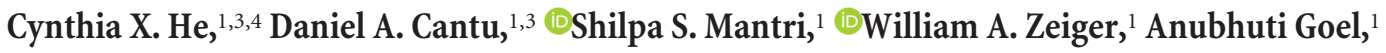 \\ and Carlos Portera-Cailliau ${ }^{1,2,4}$ \\ Departments of ${ }^{1}$ Neurology and ${ }^{2}$ Neurobiology, ${ }^{3}$ Neuroscience Interdepartmental Program, and ${ }^{4}$ UCLA-Caltech Medical Scientist Training Program, \\ David Geffen School of Medicine, University of California, Los Angeles, Los Angeles, California 90095
}

Sensory hypersensitivity is a common symptom in autism spectrum disorders (ASDs), including fragile X syndrome (FXS), and frequently leads to tactile defensiveness. In mouse models of ASDs, there is mounting evidence of neuronal and circuit hyperexcitability in several brain regions, which could contribute to sensory hypersensitivity. However, it is not yet known whether or how sensory stimulation might trigger abnormal sensory processing at the circuit level or abnormal behavioral responses in ASD mouse models, especially during an early developmental time when experience-dependent plasticity shapes such circuits. Using a novel assay, we discovered exaggerated motor responses to whisker stimulation in young Fmr1 knock-out (KO) mice (postnatal days 14-16), a model of FXS. Adult Fmr1 KO mice actively avoided a stimulus that was innocuous to wild-type controls, a sign of tactile defensiveness. Using in vivo two-photon calcium imaging of layer 2/3 barrel cortex neurons expressing GCaMP6s, we found no differences between wild-type and Fmr1 KO mice in overall whisker-evoked activity, though 45\% fewer neurons in young Fmr1 KO mice responded in a time-locked manner. Notably, we identified a pronounced deficit in neuronal adaptation to repetitive whisker stimulation in both young and adult Fmr1 KO mice. Thus, impaired adaptation in cortical sensory circuits is a potential cause of tactile defensiveness in autism.

Key words: barrel cortex; behavior; calcium imaging; development; Fragile X Syndrome; two photon

\section{Significance Statement}

We use a novel paradigm of repetitive whisker stimulation and in vivo calcium imaging to assess tactile defensiveness and barrel cortex activity in young and adult Fmr1 knock-out mice, the mouse model of fragile X syndrome (FXS). We describe evidence of tactile defensiveness, as well as a lack of L2/3 neuronal adaptation in barrel cortex, during whisker stimulation. We propose that a defect in sensory adaptation within local neuronal networks, beginning at a young age and continuing into adulthood, likely contributes to sensory overreactivity in FXS and perhaps other ASDs.

\section{Introduction}

Sensory dysfunction, especially hypersensitivity, occurs in many individuals with autism spectrum disorders (ASDs; Marco et al., 2011; Green et al., 2015). Sensory hypersensitivity (overreactiv-

Received March 7, 2017; revised May 17, 2017; accepted May 24, 2017.

Author contributions: C.X.H. and C.P.-C. designed research; C.X.H., D.A.C., W.A.Z., and A.G. performed research; C.X.H., S.S.M., A.G., and C.P.-C. analyzed data; C.X.H. and C.P.-C. wrote the paper.

This work was supported by a Paul and Daisy Soros Fellowship for New Americans (C.X.H.), NIH NINDS F30 Fellowship NS093719 (C.X.H.), UCLA Neural Microcircuits Training Grant T32-NS058280 (D.A.C.), a Eugene V. CotaRobles fellowship (D.A.C.), the UCLA Medical Scientist Training Program (NIH National Institute of General Medical Sciences Training Grant GM08042; C.X.H.), Developmental Disabilities Translational Research Program Grant 20160969 (John Merck Fund; C.P.-C.), Simons Foundation Autism Research Initiative Grant 295438 (C.P.-C.), and NIH National Institute of Child Health and Human Development Grant R01 HD054453 (C.P.-C.). We thank M. Einstein and P. Golshani (help with behavioral rig design); G. Liu (help with behavioral rig construction); P. Mineault, D. Ringach, D. Dombeck, T.-W. Chen, and K. Svoboda (MATLAB code for imaging analysis); N. Hardy (help with behavioral data analysis); N. Wisniewski (help with statistical analyses); K. Battista (P1 injection illustration); A. Keller (help with curve fitting); D. Buonomano, K. Martin, S. Masmanidis, J. Moore, D. Geschwind, M. Reimers, M. Suchard, and other Portera-Cailliau lab members (helpful discussions); and the Janelia GENIE project (AAV GCaMP6s).

The authors declare no competing financial interests. ity) commonly affects auditory, tactile, or visual processing, and may present as defensiveness or avoidance (Marco et al., 2011; Green et al., 2015; Sinclair et al., 2016). Because it likely contributes to other ASD symptoms, such as anxiety, hyperarousal and sleep disturbances, attention deficit, stereotyped behaviors or rituals, and learning difficulties (Ben-Sasson et al., 2007; Sinclair et al., 2016), sensory overreactivity is a symptom of central significance in autism.

It has been suggested that phenotypic heterogeneity in autism might not reflect a unique cellular pathology, but rather a perturbation of network properties that emerge when neurons interact (Belmonte et al., 2004). In other words, the development of ef-

Correspondence should be addressed to Dr. Carlos Portera-Cailliau, Departments of Neurology and Neurobiology, RNRC A-145, David Geffen School of Medicine, University of California, Los Angeles, 710 Westwood Plaza, Los Angeles, CA 90095. E-mail: cpcailliau@mednet.ucla.edu.

DOI:10.1523/JNEUROSCI.0651-17.2017

Copyright $\odot 2017$ the authors $\quad 0270-6474 / 17 / 376475-13 \$ 15.00 / 0$ 
fective treatments for specific functional deficits in ASD will likely require understanding the circuit-level alterations involved. This is challenging in human patients, as the methods available to assess network-level correlates of sensory dysfunction (EEG or fMRI) lack single-neuron spatial resolution. Instead, it is necessary to record network activity in vivo, with cellular resolution, in mouse models of inherited ASDs (Gonçalves et al., 2013; Lu et al., 2016).

Fragile X syndrome (FXS), in which transcriptional silencing of the Fmrl gene leads to loss of the fragile $\mathrm{X}$ mental retardation protein, is particularly compelling as a prototypical neurodevelopmental disorder in which to study circuit mechanisms underlying altered sensory processing. FXS is the most common single-gene cause of autism ( $\sim 2 \%$ of ASD cases; Wassink et al., 2001; Reddy, 2005), and the vast majority of FXS patients have tactile defensiveness (Butler et al., 1991; Hagerman et al., 1991). Additionally, the Fmr1 knock-out (KO) mouse model of FXS (The DutchBelgian Fragile X Consortium, 1994) exhibits behavioral deficits analogous to human symptoms, including audiogenic seizures and increased startle responses (Bernardet and Crusio, 2006; Contractor et al., 2015). Fmrl KO mice also show increased intrinsic excitability, delayed GABA polarity switch, reduced inhibition, and network hypersynchrony (Contractor et al., 2015). However, how such hyperexcitability leads to behavioral sensory hypersensitivity, or whether Fmr1 KO mice even exhibit an avoidance response to tactile stimuli, has not been studied.

Here, we test the hypothesis that specific abnormalities in sensory-evoked network activity in somatosensory cortex are associated with tactile defensiveness in Fmr1 KO mice. We performed a behavioral screen for tactile defensiveness in young and adult wild-type (WT) and Fmr1 KO mice as well as in vivo twophoton calcium imaging of whisker-evoked activity in layer $2 / 3$ (L2/3) neurons in barrel cortex. We sought to answer the following questions: Do Fmr1 KO mice display an impaired behavioral response to whisker stimulation, i.e., an avoidance motor response akin to tactile defensiveness? What are the circuit-level correlates of sensory hypersensitivity in neocortex that give rise to the tactile defensiveness?

\section{Materials and Methods}

Materials. Unless noted otherwise, materials were purchased from Sigma-Aldrich.

Experimental animals. All experiments followed the U.S. National Institutes of Health guidelines for animal research, under an animal use protocol approved by the Chancellor's Animal Research Committee (ARC) and Office for Animal Research Oversight at the University of California, Los Angeles (\#2007-035). All experiments used male and female FVB.129P2 WT mice (JAX line 004828, RRID: IMSR_JAX: 004828) and Fmr1 KO mice (JAX line 004624, RRID: IMSR_JAX:004624; The Dutch-Belgian Fragile X Consortium, 1994) housed in a vivarium with a $12 \mathrm{~h}$ light/dark cycle. Experiments were performed during the light cycle. Animals were weaned at postnatal day 21 (P21)-P22 and afterward housed with up to five mice per cage. Before P21, pups were housed with their dam. The FVB background was chosen because of its robust breeding, and because the FVB Fmrl KO phenotype includes a predisposition to audiogenic seizures (Bernardet and Crusio, 2006). Because of the potentially stressful effects of surgeries on pups of early prenatal ages and their dams, homozygous litters were used to maximize survival by eliminating the possibility of littermates with different genotypes receiving unequal attention from the dam.

Tactile defensiveness assay in head-restrained mice. We adapted the head-restrained paradigm as described previously (Dombeck et al., 2007), where animals are habituated to head restraint on a $200 \mathrm{~mm}$ polystyrene ball moving freely on an air cushion within a half-sphere polystyrene shell (Graham Sweet; Fig. 1a). The animal can choose to rest, whisk, or run freely in any direction, with minimal friction. For P14-P16 experiments, titanium head bars were implanted at P10-P12, and the pups were then habituated on the ball for $20 \mathrm{~min} / \mathrm{d}$ for 3 consecutive days, with the earliest age of head restraint being P11 (Fig. 1a). Before P11, we observed very little motion from the pups when on the ball. As was previously observed in freely moving pups, not only do neonatal rodents strongly prefer huddling to free exploration in the first postnatal week, they develop exploratory behavior and bilateral whisking at P11P15 (Grant et al., 2012; van der Bourg et al., 2016). For adult behavioral experiments (Fig. 2), a subset of the animals tested at P14-P16 were rehabituated for 4 consecutive days before testing at P35-P41. All 17 WT and 13 Fmr 1 KO animals tested at P35-P41 and displayed in Figure 2 had been tested previously at P14-P16.

On the test day, the animal was first placed on the ball for a $3 \mathrm{~min}$ baseline period. Next we performed a sham stimulation trial in which the whisker stimulator was visibly moving, but just out of tactile range of the animal's whiskers on its left side (Fig. 1a). The stimulator consisted of a long, narrow comb of five slightly flexible wires descending from bent glass capillaries, which were in turn attached to a piezoelectric actuator. During the stimulation trial, the wires of the stimulator were intercalated between the animal's whiskers. Whisker bundling onto a glass capillary (as used during the imaging experiments) would not have been feasible here because the mouse could have damaged the capillary or unbundled some of its whiskers with its forepaw. The stimulation protocol consisted of a $10 \mathrm{~s}$ baseline followed by 20 whisker stimulations along the anteriorposterior direction ( $1 \mathrm{~s}$ long at $10 \mathrm{~Hz}$ ), with a $3 \mathrm{~s}$ interstimulus interval (ISI), with the stimulations totaling $80 \mathrm{~s}$, ending with another $10 \mathrm{~s}$ baseline. This protocol was created based on the fact that mice tend to whisk at $5-15 \mathrm{~Hz}$ for bouts of $1-4 \mathrm{~s}$, and is consistent with published studies using a comparable frequency of $8 \mathrm{~Hz}$ (Mégevand et al., 2009) and 2-6 s ISI (Kerr et al., 2007; Heiss et al., 2008). A fast infrared camera (Allied Vision Technologies GE680) was used to monitor ball motion and animal movements.

A custom-written semiautomated video analysis routine was implemented in MATLAB to determine when the animal was moving/running versus stationary (Figs. $1 b, 2 a$ ). The videos were carefully inspected to decide whether the animal was moving forward or backward or steering left or right (left, toward whisker stimulator; right, away from stimulator) for each $1 \mathrm{~s}$ increment of video, based on the animal's forelimb movements and the movement of dots on the ball (Fig. $2 c$ ). During left/right movement, the animals' forelimbs create rhythmic sweeping motions in the opposite direction of steering, with limbs sweeping out laterally from the midline and pushing the ball to the left or right (with the ball spinning either left or right under them, respectively). During forward/backward movement, the animals' forelimbs would remain under their shoulders (close to their midline), with smooth forward/backward steps and resulting forward/backward movement of the ball. Analysis of running during the "end" of the stimulation (Fig. 1d) included the last $20 \mathrm{~s}$ of the stimulation, which covers the last five stimulations and is a time frame used during later imaging analysis.

P1 injection of AAV vector for GCaMP6s expression. rAAV (AAV1.Syn. GCaMP6s.WPRE.SV40; Chen et al., 2013) was purchased from the University of Pennsylvania Vector Core and diluted to a working titer of $2 \mathrm{E} 13$ with $1 \%$ filtered Fast Green FCF dye. Pups were anesthetized with isoflurane (5\% induction, $1.5-2 \%$ maintenance via a nose cone, $\mathrm{v} / \mathrm{v}$ ) and placed in a stereotaxic frame. A subcutaneous injection of carprofen (Rimadyl, Pfizer; $5 \mathrm{mg} / \mathrm{kg}$ ) was administered. The scalp was sterilized with alternating swabs of betadine and $70 \%$ alcohol. A small skin flap (2-3 mm in length) was made over the somatosensory cortex. The periosteum was gently cleared under the skin flap using brief, gentle touches of a dental drill. At the injection site, the bone was drilled lightly to create a small crack, permitting injection via pulled-glass capillary without exposing the dura. Glass micropipettes (Sutter Instrument, $1.5 \mathrm{~mm}$ outer diameter, $0.86 \mathrm{~mm}$ inner diameter) were used to inject $\sim 0.2 \mu \mathrm{l}$ of rAAV into the superficial cortex at a depth of $0.2 \mathrm{~mm}$ below the dura, using a Picospritzer (General Valve; Fig. 3a, left). After removing the pipette, the injection site was sealed with a small drop of VetBond (3M). The skin flap was replaced, and the skin edges were sealed with VetBond. The entire surgery was completed in 15-20 min per animal. The pup was allowed to 
a

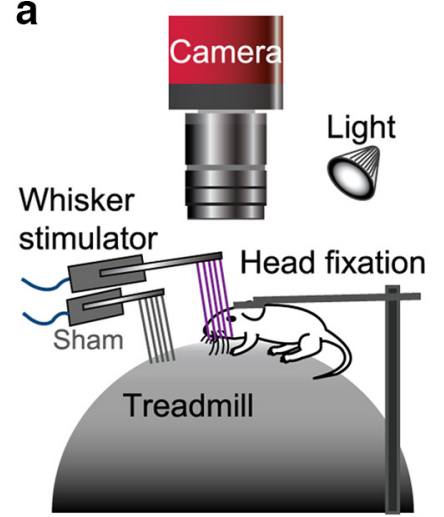

Day

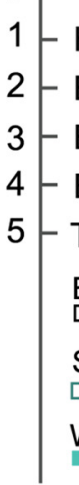

Headbar implantation

2 - Ball habituation (20 min)

3 - Ball habituation

4 - Ball habituation

5 - TEST DAY:

Baseline (3 min) - no stims

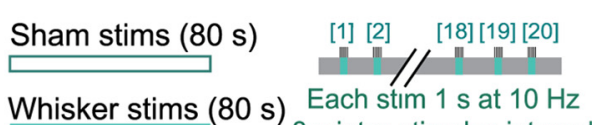

b

Stationary Moving

WT P14-16 $(n=21)$
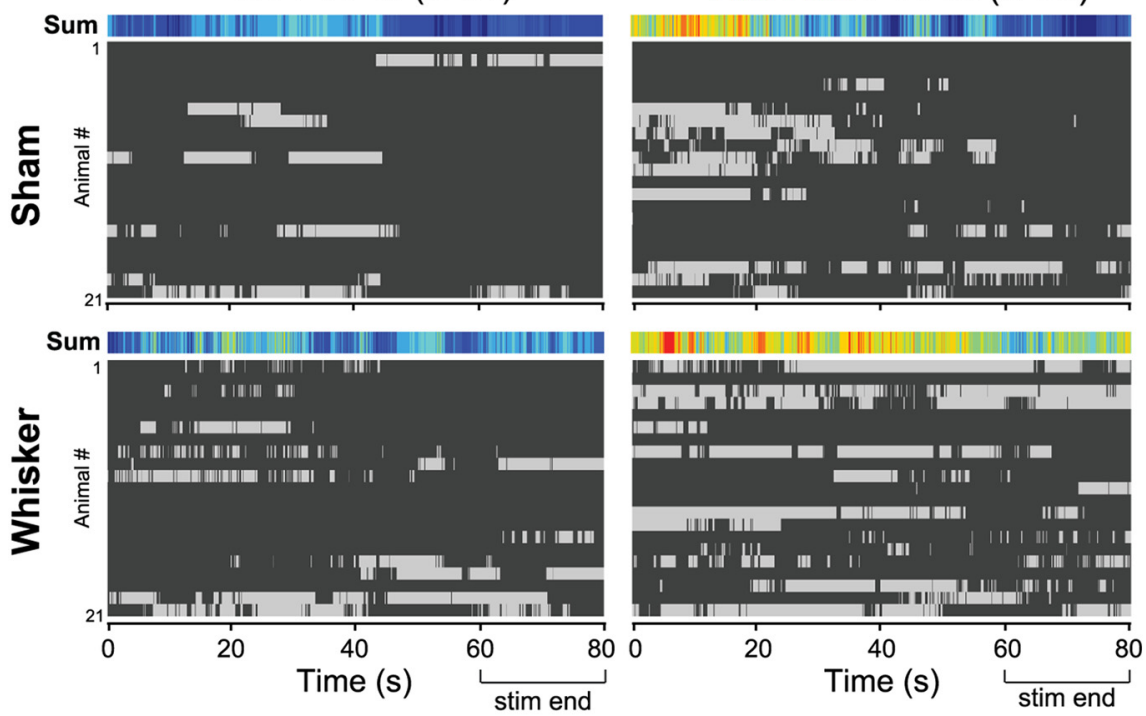

C

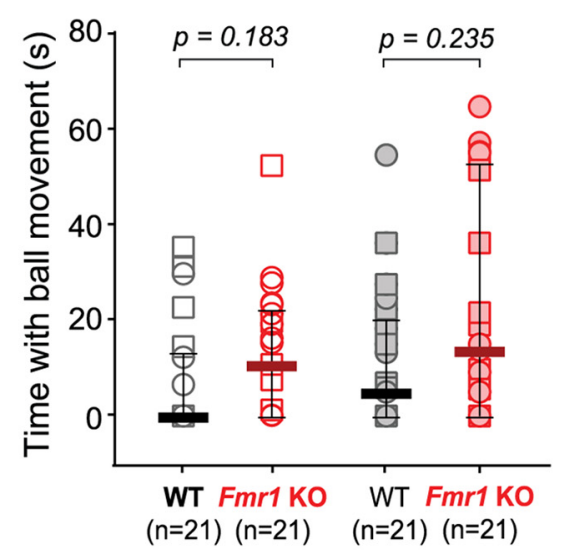

Sham stim Whisker stim (80 s) d

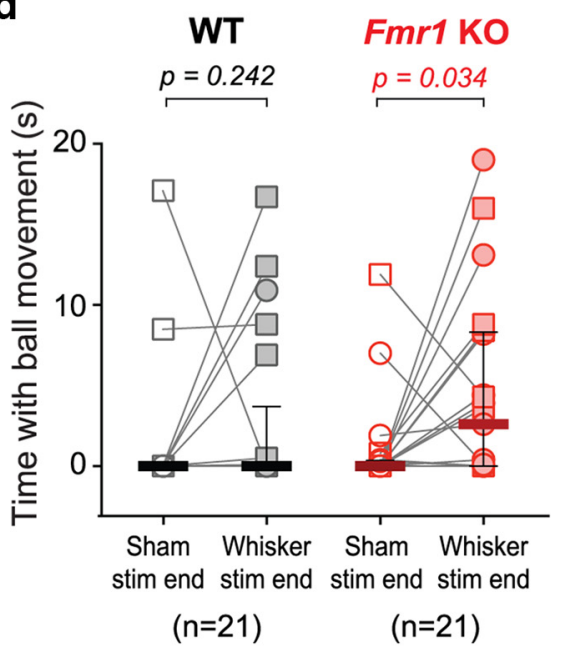

Figure 1. Increased locomotion of $F m r 1 \mathrm{~K} 0$ mice at P14-P16 during repeated whisker stimulation. $\boldsymbol{a}$, Diagram of behavioral assay setup (left) and timeline of protocol (right). A whisker stimulator comb of flexible wires, moved by a piezoelectric actuator, was placed in front of but not in contact with the whiskers (sham) or was intercalated between whiskers on the left snout (whisker stimulation) as shown. $\boldsymbol{b}$, Locomotion of WT and Fmr 1 K0 mice ( $n=21$ per genotype), P14-P16, during 20 sham and whisker stimulations (each $1 \mathrm{~s}$ with $3 \mathrm{~s} \mid \mathrm{SI})$. Each row represents one animal. Dark gray means mice were stationary, and light gray means they were moving (see Materials and Methods). Colored heat map shows the $\%$ of mice moving at any given time (cumulative recover on a warm water circulation blanket before being returned to the dam.

Cranial window surgery for P14-P16 imaging. Pups (P10-P12) were anesthetized with isoflurane $(5 \%$ induction, $1.5-2 \%$ maintenance via a nose cone, $\mathrm{v} / \mathrm{v}$ ) and placed in a stereotaxic frame. A $2.5-3.5 \mathrm{~mm}$ diameter craniotomy was performed over the right barrel cortex and covered with a 3 or $5 \mathrm{~mm}$ glass coverslip, as described previously (Mostany and Portera-Cailliau, 2008; Golshani et al., 2009). A head bar was also attached to the skull with dental cement to secure the animal to the microscope stage. The cranial window surgery itself can be done in under $60 \mathrm{~min}$, and our protocol and custom head bars were designed to facilitate postoperative reintegration into the litter. Within $2 \mathrm{~h}$ after surgery, the pups appeared fully recovered from the effects of anesthesia and were able to nurse normally.

Cranial window surgery with $A A V$ vector injection for adult GCaMP6s imaging. For 8 of the $10 \mathrm{WT}$ adult animals and 5 of the $8 \mathrm{Fmr} 1$ $\mathrm{KO}$ adult animals imaged, the AAV1.Syn. GCaMP6s.WPRE.SV40 vector was injected into the barrel cortex during the cranial window surgery, $2+$ weeks before imaging, following existing protocols (Chen et al., 2013). After drilling a $4 \mathrm{~mm}$ craniotomy over the right barrel cortex, $\sim 30 \mathrm{nl}$ of rAAV vector, diluted to a working titer of $2 \mathrm{E} 13$ with $1 \%$ filtered Fast Green, was injected into four to seven sites in the barrel cortex. The craniotomy was covered with a $5 \mathrm{~mm}$ glass coverslip, and a head bar was also attached to the skull with dental cement.

The remaining two WT adult animals and one of the remaining $\mathrm{KO}$ animals had been injected with rAAV vector at $\mathrm{P} 1$ and received cranial window implantation at $\mathrm{P} 10-\mathrm{P} 12$, following the previously described protocol, but were not used for the P14-P16 imaging experiments. The remaining two of eight $\mathrm{KO}$ adult animals had been injected with $\mathrm{rAAV}$ vector at $\mathrm{P} 1$, had received cranial window implantation at P10-P12, and had also been used for the P14-P16 imaging experiments.

Optical intrinsic signal imaging. Following cranial window surgery, optical intrinsic signal (OIS) imaging was used to map the barrel cortex at P12-P14 (for P14-P16 imaging) or at least $1 \mathrm{~d}$ before imaging (for adults). As described previously (Johnston et al., 2013), the contralateral whisker bundle was gently attached using bone wax to a glass needle coupled to a piezoactuator (Physik Instrumente). Each stimulation trial consisted of a $100 \mathrm{~Hz}$ sawtooth stim-

$\leftarrow$

locomotion). c, Total time spent moving during entire $80 \mathrm{~s}$ of sham and whisker stimulations for WT and Fmr1 K0 mice. In $c, p$ values are from unpaired rank-based two-group comparisons with 10,000 resamples and Bonferroni correction. $\boldsymbol{d}$, Time spent moving during last $20 \mathrm{~s}$ of sham and whisker stimulations for WT and Fmr $1 \mathrm{KO}$ mice. $p$ values are from pairwise rank-based two-group comparisons with 10,000 resamples and Bonferroni correction. In $\mathbf{c}$ and $\boldsymbol{d}$, circles represent female mice and squares represent male mice, bars represent group medians, and error bars represent first/third quartiles. 
a
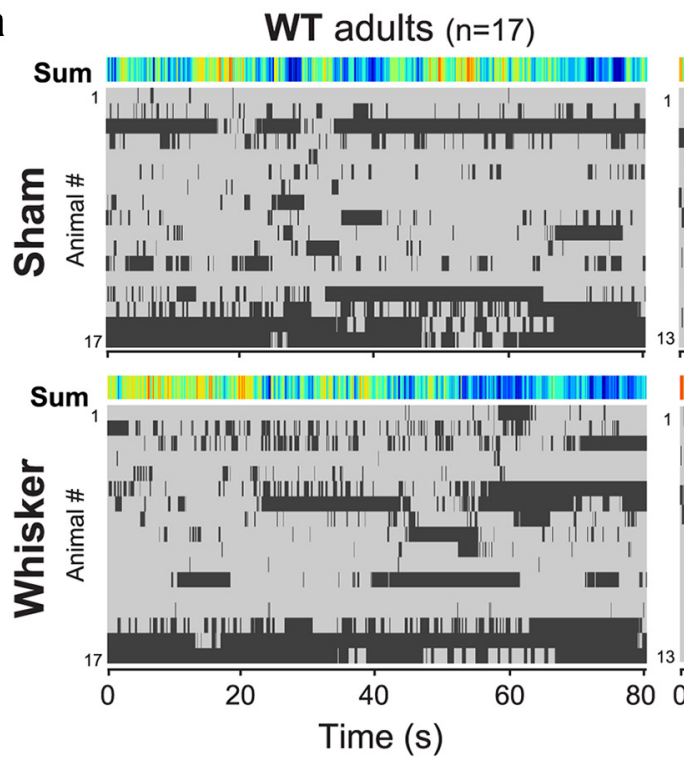

Fmr1 KO adults $(\mathrm{n}=13)$
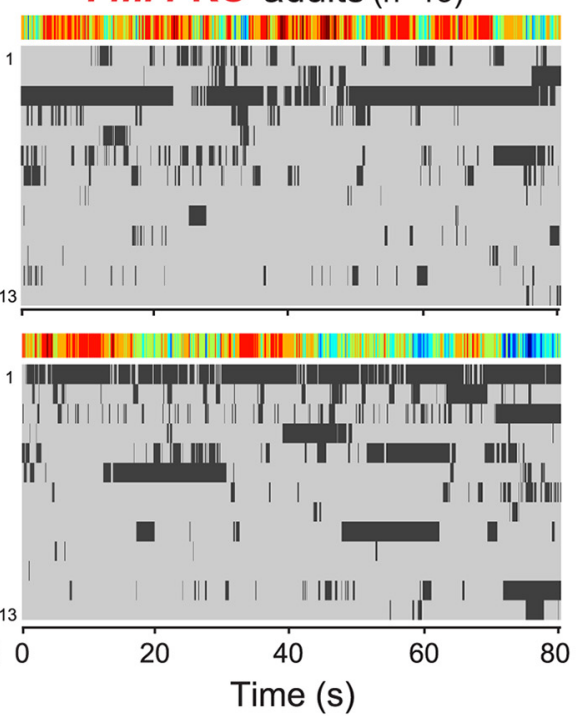

Stationary

Running

$\%$ mice running

100 b

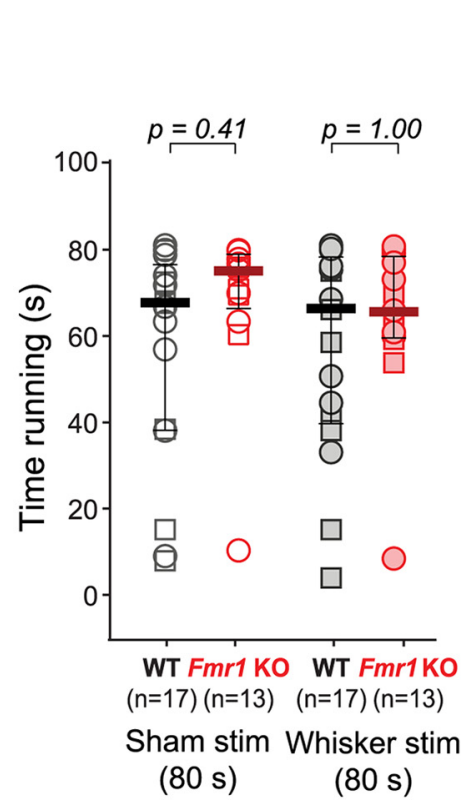

C WT adults $(\mathrm{n}=17)$

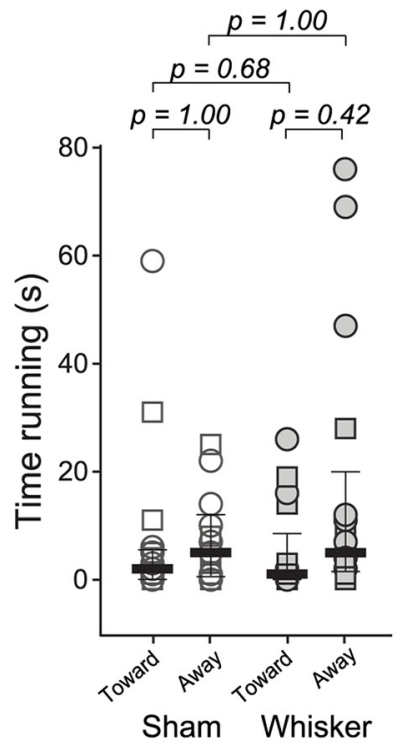

(80 s)
Fmr1 KO adults ( $\mathrm{n}=13)$

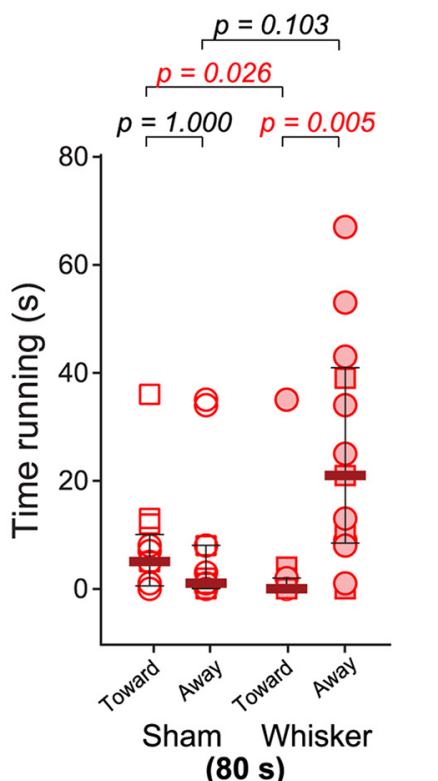

Figure 2. Adult Fmr1 K0 mice show tactile defensiveness during repeated whisker stimulation. $\boldsymbol{a}$, Running of WT $(n=17)$ and Fmr $\mathrm{KO}(n=13)$ adult mice (P35-P41) during repetitive sham and whisker stimulation (as in Fig. 1b). Note that the adult mice show much higher rates of locomotion than the P14-P16 mice. $\boldsymbol{b}$, Total time spent running during entire 80 s of sham and whisker stimulations for WT and Fmr $1 \mathrm{KO}$ mice. In $\boldsymbol{b}, p$ values are from unpaired rank-based two-group comparisons with 10,000 resamples and Bonferroni correction. $\boldsymbol{c}$, Total time spent running toward (left) or away (right) from whisker stimulator for WT and Fmr $1 \mathrm{KO}$ mice during the $80 \mathrm{~s}$ of sham and whisker stimulations. $p$ values are from pairwise rank-based two-group comparisons with 10,000 resamples and Bonferroni correction. In $\boldsymbol{b}$ and c, circles represent female mice, squares represent male mice, bars represent group medians, and error bars represent first/third quartiles.

ulation lasting $1.5 \mathrm{~s}$. The response signal divided by the averaged baseline signal, summed for all trials, was thresholded at a fraction $(65 \%)$ of maximum response to delineate the cortical representation of stimulated whiskers (Fig. 3b). OIS signal intensities were not quantified, nor were they compared between animals.

In vivo two-photon calcium imaging in head-restrained mice. Calcium imaging was performed on a custom-built two-photon microscope with a Chameleon Ultra II Ti:sapphire laser (Coherent), a $20 \times$ objective $(0.95$ numerical aperture, Olympus), and ScanImage software (Pologruto et al., 2003; RRID: SCR_014307). Mice were lightly sedated with chlorprothixene $(2 \mathrm{mg} / \mathrm{kg}$, i.p. $)$ and isoflurane $(0-0.5 \%)$ and kept at $37^{\circ} \mathrm{C}$ using a temperature control device and heating blanket (Harvard Apparatus). The isoflurane was manually adjusted to maintain a breathing rate ranging from 100-150 breaths/min for P14-P16 mice and 140-150 breaths/ min for adult mice. Both spontaneous activity and whisker-evoked barrel cortex activity were recorded. Whisker stimulation was delivered by bundling the contralateral whiskers (typically all macrovibrissae of at least $\sim 1 \mathrm{~cm}$ in length), via soft bone wax, to a glass needle coupled to a piezoactuator (Fig. $3 a$, right). The stimulation protocol was the same as that used during behavioral experiments (Fig. $3 d$ ). Whole-field images were acquired at $7.8 \mathrm{~Hz}(1024 \times 128$ pixels downsampled to $256 \times 128$ pixels; Fig. 3c).

Data analysis for calcium imaging. Calcium-imaging data were analyzed using custom-written MATLAB routines (MATLAB version 2014a, RRID: SCR_001622), which included modifications over previously described MATLAB code (Golshani et al., 2009; Gonçalves et al., 2013). In 4 of 20 movies of P14-P16 spontaneous activity (1600 frames acquired), between 8 and 34 frames with significant $Z$ motion were manually re- 
a

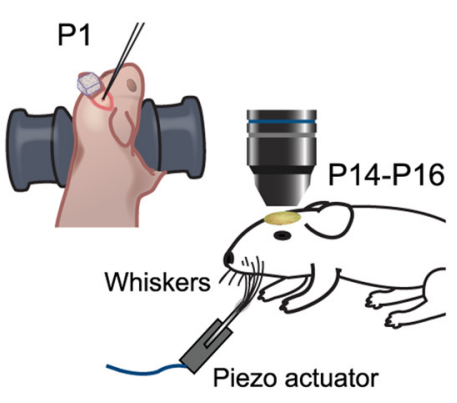

b

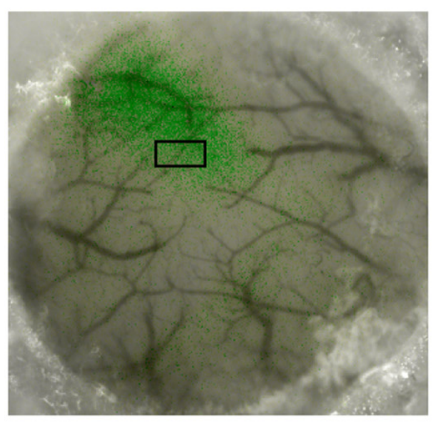

C

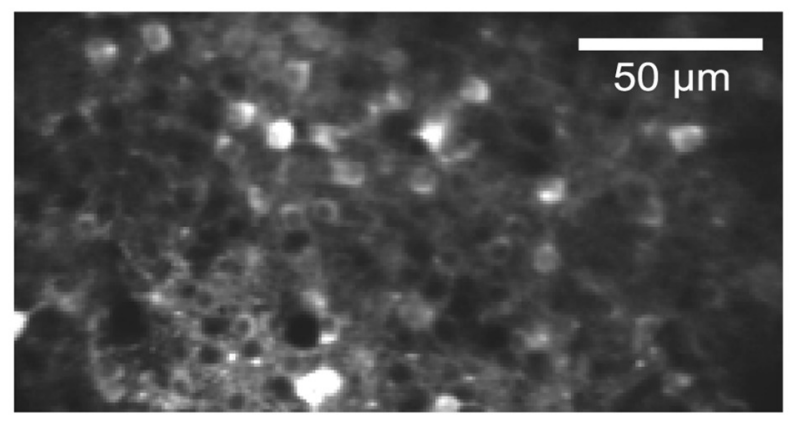

d

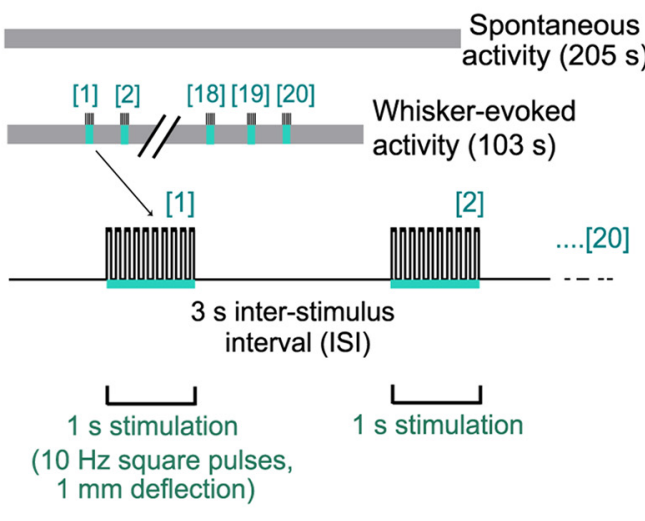

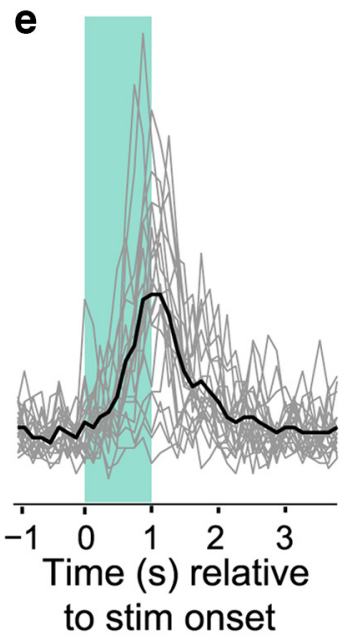

f Spontaneous

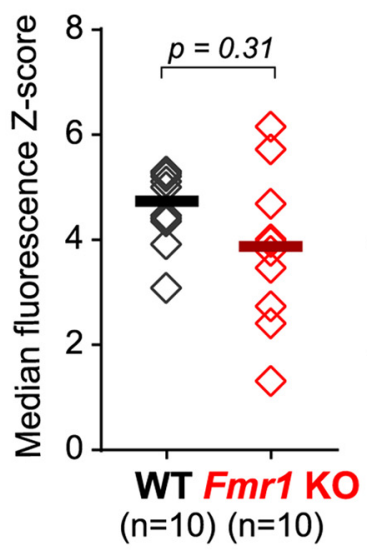

Evoked (20 stims)

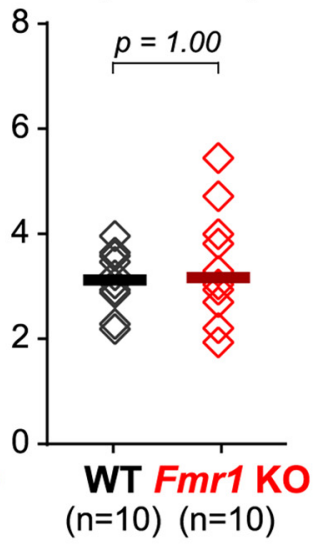

\section{g}

\section{Time-locked to whisker stim:}

Cell 1 1

Cell 2

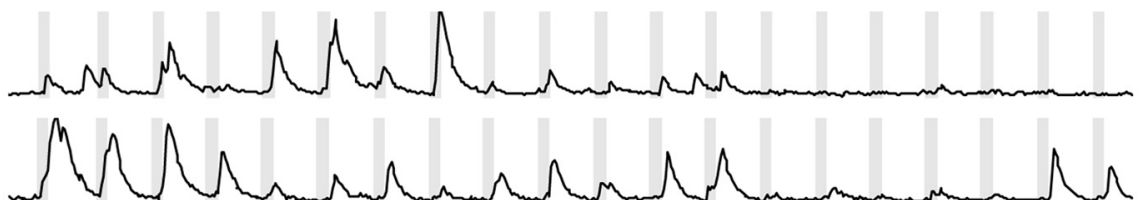

Non-time-locked:

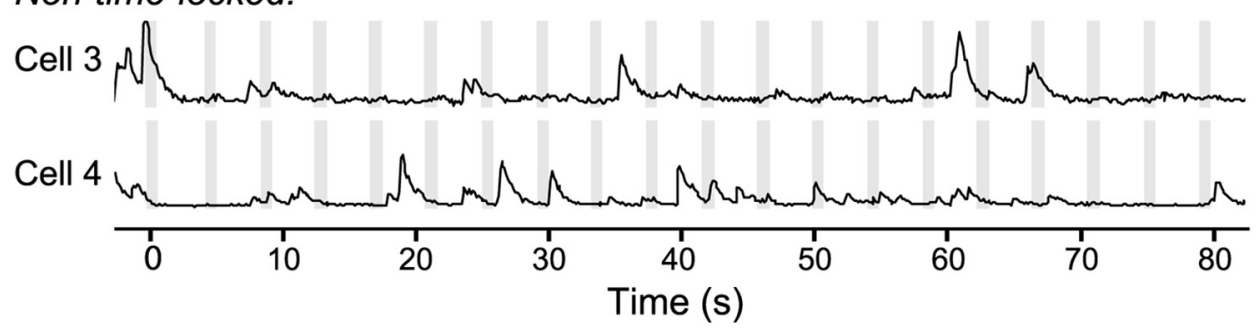

\section{h}

Figure 3. Differences in whisker-evoked network activity in Fmr1 K0 mice at P14-P16. a, Schematic of how AAV vector for GCaMP6s injection was injected into somatosensory cortex at P1 (left) and P14-P16 in vivo imaging and whisker stimulation setup (right). $\boldsymbol{b}$, Example cranial window over right somatosensory cortex at P14 and a map of whisker-evoked activity obtained with optical intrinsic signal imaging (green). The black box shows the location of in vivo calcium imaging in c. c, Example field of view of neurons in barrel cortex expressing GCaMP6s in the same mouse (at P15) shown in $\boldsymbol{b}$ at P15 (xyt sum projection of 100 consecutive frames at $7.8 \mathrm{~Hz}$ ). $\boldsymbol{d}$, Protocol for recording spontaneous (1600 frames $\approx 205 \mathrm{~s}$ ) and whisker-evoked activity ( $800 \mathrm{frames} \approx 103 \mathrm{~s}$ ). $e$, Example of individual fluorescent signals extracted from one L2/3 neuron during 20 whisker stimulations (gray) and the mean signal (black) showing how single neurons in barrel cortex can respond to repeated stimulations. $f$, Median fluorescence $Z$ scores for spontaneous (left) and whisker-evoked activity (right) of L2/3 neurons in WT and Fmr 1 K0 mice at P14 -P16 ( $n=$ 10 mice per genotype). Each diamond shows the median $Z$ score across all ROls for one animal, for equivalent durations of spontaneous and evoked imaging (103 s). Bars represent group medians. In $\boldsymbol{f}$ and $\boldsymbol{h}, p$ values are from two-group rank-based comparisons with 10,000 resamples, and Bonferroni correction in $\boldsymbol{f}$. For the experiments shown in Figures 3 and 4 , we did not track the sex of the mice. $g$, Example fluorescence traces from two $L 2 / 3$ neurons with activity that is time-locked (top) and from two different neurons with activity that is not time-locked (bottom) to whisker stimulation epochs (light gray bars). $\boldsymbol{h}$, Local networks in barrel cortex of $F m r 1 \mathrm{~K} 0$ animals have $50 \%$ fewer time-locked L2/3 neurons compared with WTs. 
moved before motion correction. In 1 of 20 movies of P14-P16 evoked activity ( 800 frames), 24 frames with $Z$ motion occurred during the initial $10 \mathrm{~s}$ of baseline acquisition before whisker stimulation began, allowing replacement of these frames with an averaged $Z$ projection of the remainder of the video. In 11 out of 20 movies of P34-P74 spontaneous activity (1600 frames acquired), some frames (up to 420 ) exhibiting $Z$-axis motion were manually removed before motion correction. Subsequent data quantifications used only the first 800 frames of spontaneous activity, i.e., an equivalent duration as the evoked activity.

$X-Y$ drift in the movies was then corrected using either a frame-byframe, hidden Markov model-based registration routine (Dombeck et al., 2007) or a cross-correlation-based, nonrigid alignment algorithm (Mineault et al., 2016). The choice of registration algorithm did not affect the data analysis, since the fluorescence data for each neuron was always normalized to its own baseline. A semiautomated algorithm (Chen et al., 2013) was used to select regions of interest, each representing a single cell body, and extract the fluorescence signal $(\Delta F / F)$ for each neuron. A "modified $Z$ score" $Z \_F$ vector for each neuron was calculated as $Z \_F=$ $[F(t)-$ mean (quietest period)]/SD(quietest period), where the quietest period is the $10 \mathrm{~s}$ period with the lowest variation (standard deviation) in $\Delta F / F$. All subsequent analyses were performed using the $Z \_F$ vectors.

To define whether an individual cell showed time-locked responses to whisker stimulations (Figs. $3 g, h, 5 b$ ), a probabilistic bootstrapping method was implemented. First, we calculated the correlation between the stimulus time course and the $Z_{-} F$ vector, followed by correlation calculations between the stimulus time course and 10,000 scrambles of all calcium activity epochs in $Z \_F$ (an epoch was consecutive frames wherein $Z \_F \geq 3$ ). The 10,000 comparisons generated a distribution of correlations ( $R$ values), within which the correlation of the unscrambled data and the stimulus fell at a certain percentile. If the calculated percentile for a cell was $<0.01$, then we described that cell as being time locked.

For analysis of aggregate activity within a particular time range, as in Figures $3 f, 4 d-f$, and $5 a$ or $c-e$, the mean of $Z_{-} F$ within that time range was calculated for each ROI, and for each animal imaged, a median $Z \_F$ was then calculated across all ROIs or a subset of ROIs (e.g., only timelocked or non-time-locked ROIs). The initial and end baseline periods of evoked activity were included in the analyses for Figures $3, f$ and $h$, and $5, a$ and $b$.

For curve fitting of WT neuronal activity across stimulations (Fig. 4c), we calculated the median $Z_{-} F$ across ROIs for each animal imaged, within each of the 20 stimulations (from $0.2 \mathrm{~s}$ before stimulation onset to $2.8 \mathrm{~s}$ after stimulation end), and then applied iterative nonlinear, leastsquares curve fitting with the Levenberg-Marquardt algorithm. The best-fit exponential curve to all data points for each stimulation had the equation $y=A e^{-\mathrm{x} / \tau}+o f f$, where $A=1.94 \pm 0.25, \tau=4.10 \pm 1.26$, and off $=1.42 \pm 0.14$.

To analyze the correlation between the WT and Fmr1 KO animals' proportions of time-locked neurons and their respective adaptation indices of activity (Fig. $4 g$ ), we calculated an adaptation index as [ $Z$ score during first five stimulations $)-(Z$ score during last five stimulations $)] /[(Z$ score during first five stimulations $)+(Z$ score during last five stimulations)].

Statistical analyses. Central tendencies are reported in the main text as group median plus or minus median absolute deviation. Graphs show all data points as well as group medians and, where error bars are shown, interquartile ranges. Based on our group sizes of $n=8-10$ for imaging data comparisons and $n=13-21$ for behavioral data comparisons, normality cannot be ensured, and tests of normality and variance are also unreliable. As such, we implemented a conservative statistical approach of all rank-based comparisons with bootstrapping (10,000 resamples), without assumptions regarding normality or variance. These comparisons were implemented using custom-written R code (R Project for Statistical Computing, RRID: SCR_001905). Paired rank-based comparisons were used when comparing measurements within the same animals (e.g., median fluorescence $Z$ scores during the first five vs last five stimulations in WT mice). Unpaired rank-based comparisons were used when comparing measurements in different animals (e.g., percentage of time-locked neurons in WT vs Fmr1 KO mice). Two-sided $p$ values were calculated for each comparison, and Bonferroni corrections for multiple comparisons were applied where appropriate. The threshold for significance was set at $p<0.05$.

No statistical test was used to prospectively calculate sample sizes. Target sample sizes were based on previous work from our group (Golshani et al., 2009; Gonçalves et al., 2013) and equal or exceed sample sizes for other recent studies using in vivo calcium imaging and head-fixed behavior. Experimenters were aware of the genotype of the animals in each experiment, as homozygous litters were used. Both male and female animals were used.

All relevant data, MATLAB code, and R code are available upon request to the authors.

\section{Results}

\section{Exaggerated motor response to tactile stimulation in}

\section{2-week-old Fmr1 KO mice}

Because sensory hypersensitivity and tactile defensiveness in FXS and autism present in early childhood, we focused our initial studies on young mice at P14-P16. This is a critical period when sensory experience drastically shapes cortical circuits, as mice open their eyes and begin actively whisking (Arakawa and Erzurumlu, 2015). Certainly the trajectory and timing of mouse neurodevelopment do not correspond perfectly to human brain development. However, as far as the neurodevelopmental events involved in maturation of somatosensory cortex, including the desynchronization of spontaneous network activity, P14-P16 in mice grossly corresponds to the human period between the third trimester and the earliest months of life (Workman et al., 2013).

We first considered whether Fmr1 KO mice might display an avoidance response to whisker stimulation that is reminiscent of tactile defensiveness in humans with autism. No previous study has assessed behavioral responses to whisker stimulation at P14P16; instead, behavioral phenotyping of Fmr1 KO mice and other ASD models has relied on adult animals and on assessments of acute startle response (Bernardet and Crusio, 2006; Orefice et al., 2016; Sinclair et al., 2016). Thus, we developed an assay to detect abnormal behavioral responses to repetitive whisker stimulation (as a potentially aversive tactile stimulus to mice of one or both genotypes) in head-restrained animals and demonstrated its utility for testing avoidance in both young (P14-P16) and adult (P35-P41) mice. The animals were awake and head fixed but able to run freely on a floating polystyrene ball treadmill (Fig. 1a, see Materials and Methods). After a 3 min baseline, we performed a sham stimulation trial during which a flexible wire stimulator was placed in front of the mouse but out of whisker range, to control for any visual startle. The stimulation lasted $80 \mathrm{~s}$ and consisted of 20 sequential $1 \mathrm{~s}$ stimulations at $10 \mathrm{~Hz}$ (anterior-posterior), with a 3 s ISI. After the sham stimulation, the stimulator was intercalated between whiskers on the left snout, $\sim 5 \mathrm{~mm}$ from the skin, and the same stimulation protocol was delivered.

Because of their young age, not all of the P14-P16 animals moved on the treadmill (Fig. $1 b$ ). We found that compared to WT mice, a higher proportion of Fmr1 KO animals moved during both sham and whisker stimulation conditions (13/21 during sham stimulation and $15 / 21$ during whisker stimulation vs $7 / 21$ and $11 / 21$ for the WT group, respectively; Fig. $1 b$ ). This was an indication that Fmr1 KO mice overreact to tactile stimulation. However, despite previous reports of hyperactivity in adult Fmr1 KO mice (Bernardet and Crusio, 2006), we did not find a significant difference in the total time spent moving between WT and Fmr1 KO mice during the 3 min baseline period, in the absence of any sham or real (whisker) stimulation $(17.1 \pm 16.7 \mathrm{~s}$ vs $27.8 \pm$ $18.8 \mathrm{~s}$, respectively; $p=0.20$ by rank-based two-group comparison with resampling; data not shown). We also did not find in- 
a

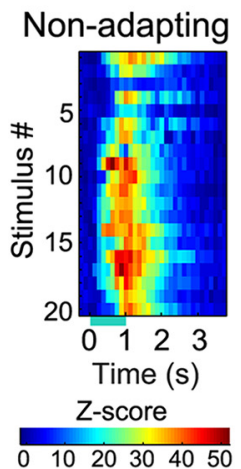

d

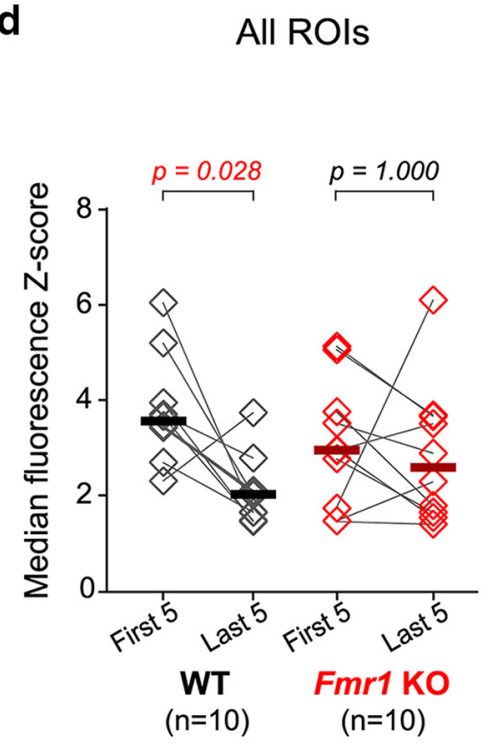

f Spontaneous activity, all ROIs Equivalent time bins as Evoked

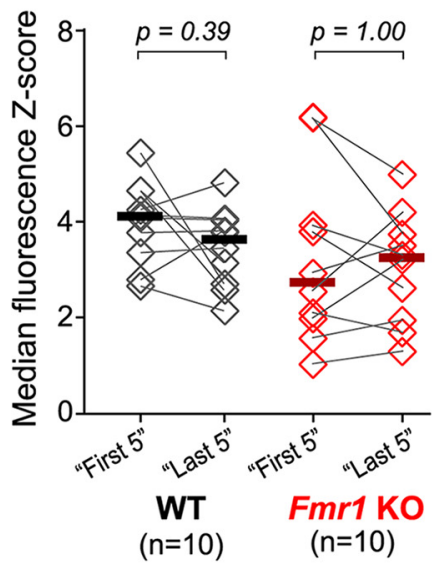

C
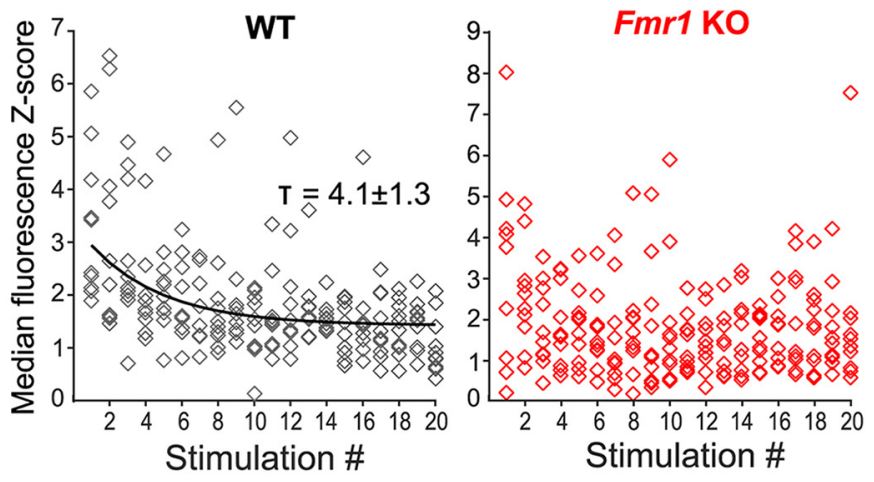

e

\section{Non-time-locked} ROls

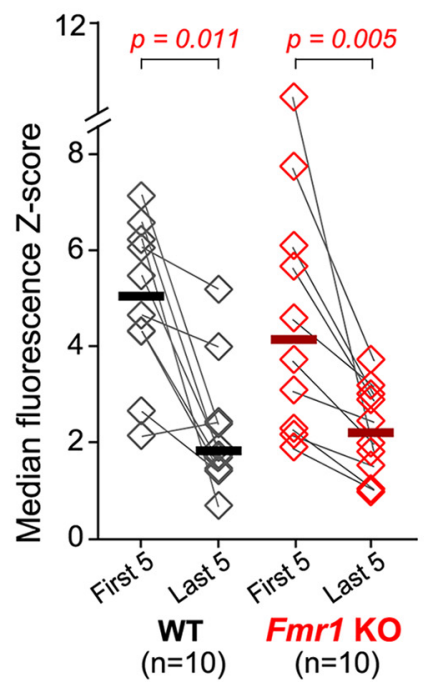

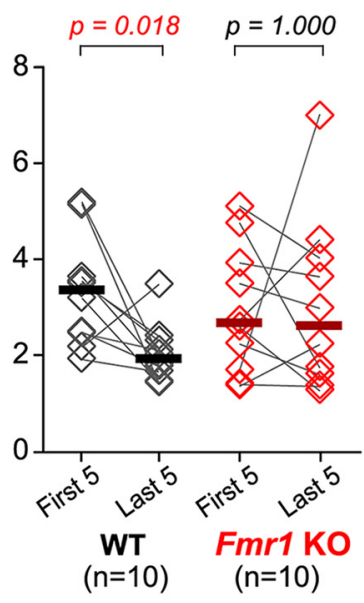

\section{g}

Spearman's $\rho=0.733$

$$
p=0.021
$$

Spearman's $\rho=0.273$

$$
p=0.436
$$

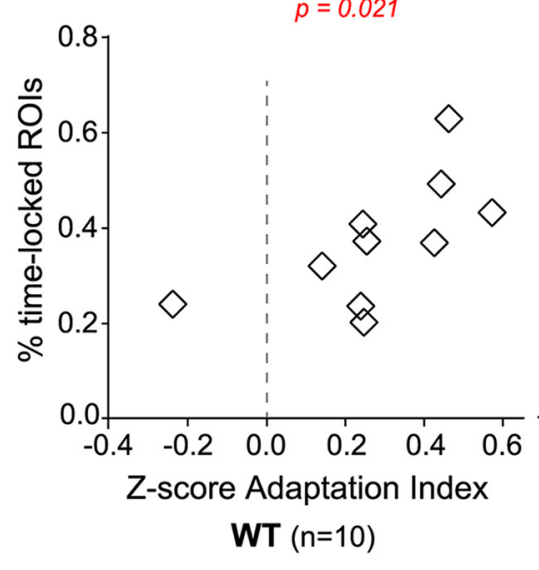


creased time running over the $80 \mathrm{~s}$ sham or whisker stimulation periods (Fig. 1c).

We developed this assay under the assumption that in headfixed mice (both young and adult), increased locomotion might reflect an avoidance response to a potentially aversive stimulus. We hypothesized that young Fmrl KO mice would show increased locomotion only to ongoing real whisker stimulation (as an escape response), whereas WT mice would show comparable locomotion during real and sham stimulation. In other words, WT animals can habituate behaviorally to tactile stimulation, but Fmr1 KO mice cannot. As such, we compared locomotion between the start (first $20 \mathrm{~s}$ ) and the end (last $20 \mathrm{~s}$ ) of the sham stimulation and real whisker stimulation. We found that the WT mice did not show a difference in locomotion between these time bins during either sham or whisker conditions ( $p=0.871$ and $p=1.000$, respectively, by paired two-group comparisons with Bonferroni correction; data not shown). In contrast, $\mathrm{KO}$ mice showed much less locomotion during the end of sham stimulation ( $p=0.051)$, but no significant habituation during the whisker stimulation ( $p=1.000$; data not shown). We then confirmed this difference in habituation by comparing locomotion during only the last $20 \mathrm{~s}$ of the sham stimulation versus the end of the real whisker stimulation. We found that in WT, the total locomotion time was not different between the two ( $p=0.242$ by paired two-group comparison with Bonferroni correction; Fig. 1d). In contrast, Fmrl KO animals showed a clear increase in running during the end of the whisker stimulation $(p=0.034)$, demonstrating a heightened reaction to the repeated tactile stimulation (Fig. 1d).

\section{Evidence of tactile defensiveness in adult Fmr1 KO mice}

Because early postnatal mice have underdeveloped gross motor skills, we could not determine whether increased locomotion on the treadmill represented a true escape response. Thus, we tested whether adult mice manifest a more obvious avoidance response, namely, steering away from the source of stimulation. We used a subset of the mice tested previously at P14-P16 and again assayed their behavioral responses to repetitive whisker stimulation at P35-P41. Adult mice showed nearly constant running on the treadmill (Fig. 2a), with speeds comparable to those observed in the open field (Niell and Stryker, 2010). The total time running during the sham or whisker stimulations was not different between genotypes ( $p=0.41$ and $p=1.00$ by two-group comparisons; Fig. 2b). WT animals showed no significant differences in steering direction during the entire $80 \mathrm{~s}$ of either sham or real whisker stimulation ( $p=1.00$ for sham by two-group comparison, $p=0.42$ for real stimulation; Fig. $2 c$, left). In contrast, Fmr 1 $\mathrm{KO}$ mice showed significantly more steering away from (and less steering toward) the stimulator during whisker stimulation ( $p=$ 0.005 ; Fig. $2 c$, right), whereas they showed no directionality during sham ( $p=1.000$; Fig. $2 c$, right). Hence, adult Fmrl KO mice display a clear avoidance behavior to repeated whisker stimulation, akin to tactile defensiveness.

\section{A reduced fraction of $\mathrm{L} 2 / 3$ neurons in barrel cortex respond to whisker stimulation in P14-P16 Fmr1 KO mice}

In light of these maladaptive whisker-induced behavioral responses that are already present in young Fmrl KO mice, we considered the underlying cortical circuit alterations in early postnatal development. P14-P16 is a critical period in sensory processing because the pattern of neuronal activity in barrel and visual cortices has just undergone a marked transition from high synchrony to a decorrelated and more computationally efficient state (Golshani et al., 2009; Rochefort et al., 2009; Frye and MacLean, 2016; O'Donnell et al., 2017). We tested three possible cortical mechanisms underlying sensory hypersensitivity in Fmr1 KO mice: (1) neurons exhibit higher-than-normal firing rates in response to sensory stimulation, (2) a higher proportion of neurons respond to stimulation, and (3) neurons show reduced adaptation (desensitization) to repetitive sensory stimuli. We considered the latter possibility especially likely, based on the lack of behavioral adaptation to whisker stimulation we observed in Fmr1 KO mice.

To record whisker-evoked activity in L2/3 neurons of the barrel cortex, we used in vivo two-photon imaging of GCaMP6s signals (Chen et al., 2013) in P14-P16 mice. First, we injected AAV1.Syn.GCaMP6s.WPRE.SV40 at P1, and then implanted a glass-covered cranial window at P10-P12. We confirmed our targeting of barrel cortex with optical intrinsic signal imaging at P12-P15 (see Materials and Methods; Fig. 3a-c). During imaging, the animals were head fixed, awake, and lightly sedated with isoflurane $(<0.5 \%)$ and chlorprothixene. We first recorded spontaneous activity (205s), followed by whisker-evoked activity (103 s), for which the animals received the same stimulation direction, timing, and frequency as during the behavioral experiments (Fig. 3d,e). We did not find significant differences between WT and Fmr1 KO mice in equivalent periods of spontaneous or whiskerevoked activity (spontaneous, median fluorescence $Z$ score \pm median absolute deviation was $4.73 \pm 0.43$ for WT vs $3.85 \pm 0.98$ for Fmr1 KO, $p=0.31$ by two-group comparison; evoked, $3.13 \pm$ 0.39 for WT vs $3.14 \pm 0.74$ for Fmrl KO, $p=1.00$; Fig. $3 f$ ).

Next, we asked whether whisker stimulation recruits a largerthan-normal cohort of barrel cortex neurons in Fmr1 KO mice. To do so, we calculated the proportion of L2/3 neurons that responded to whisker stimulation in a time-locked fashion (see Materials and Methods, Fig. 3g). Unexpectedly, we found that nearly half $(45 \%)$ as many neurons exhibited an activity pattern that was time locked to epochs of whisker stimulation in Fmr1 KO compared to WT mice $(37.2 \pm 9.1 \%$ of WT neurons vs $20.5 \pm 13.0 \%$ of Fmr1 KO neurons; $p=0.022$ by two-group comparison; Fig. 3h). This suggests that the behavioral overreactivity that Fmrl KO mice manifest is not due to either exaggerated sensory-evoked firing of local networks in barrel cortex or to higher proportions of neurons within local networks being recruited by whisker stimulation.

To determine whether the structure of sensory-evoked network activity differs between WT and Fmrl KO mice, we also compared the timing of peak activity relative to the onset of whisker stimulation. After sorting all whisker-responsive cells by the timing of their peak extrapolated firing rate relative to the stimulation onset, we did not find a difference in the two genotypes' temporal distributions (data not shown). At the spatial ( $\sim 1$ barrel) and temporal ( $\sim 125 \mathrm{~ms} / \mathrm{bin})$ scales we examined, sensoryevoked activity propagates at comparable rates in WT and Fmr1 KO barrel cortex.

Impaired adaptation of local whisker-evoked neuronal activity in P14-P16 Fmr1 KO mice persists into adulthood Our experimental design allowed us to determine whether L2/3 neurons exhibit any adaptation during the 20 sequential whisker deflections, i.e., a reduction in firing with successive stimulations. We found that some L2/3 neurons showed robust adaptation, while others did not (Fig. $4 a, b$ ). When we analyzed whiskerevoked activity of all neurons imaged in each P14-P16 WT animal, we found that the decrease in activity over time could be fit by an exponential curve with a decay constant $\tau=4.1 \pm 1.3$ 
stimulations (Fig. $4 c$, left). However, the Fmr1 KO mice did not show this clear decay in activity over time (Fig. $4 c$, right). Based on the activity decay in the WT mice, we compared neuronal activity during the first five stimulations with activity during the last five stimulations. This analysis revealed that in WT mice at P14-P16, neuronal activity was significantly lower during the last five stimulations than during the first five $(Z$ scores, $3.56 \pm 0.27$ vs $2.02 \pm 0.38, p=0.028$ by two-group comparison; Fig. $4 d$ ). In sharp contrast to WT mice, there was no significant change for Fmr1 KO mice in neuronal activity from the first five to last five stimulations $(2.95 \pm 1.01$ vs $2.59 \pm 0.99, p=1.000$; Fig. $4 d)$, suggesting that neural circuits in the mutant mice are unable to adapt to repetitive tactile stimuli.

We then wondered whether neuronal adaptation might only be evident in cells that responded to whisker stimulation in a time-locked fashion. The subpopulation of time-locked cells showed robust adaptation in both WT and Fmrl KO mice at P14-P16 (WT, $p=0.011$ by two-group comparison; Fmr1 KO, $p=0.005$; Fig. $4 e$, left). Interestingly, while non-time-locked cells also showed significant adaptation in WT mice, they did not in Fmr1 KO mice (WT, $p=0.018$; Fmr1 KO, $p=1.000$; Fig. $4 e$, right). It appears that the lack of modulation of the activity of non-time-locked cells in the young Fmr1 KO mice contributes to the defect in overall network adaptation during repetitive whisker stimulation. As a control for possible effects of continuous calcium imaging, we analyzed spontaneous activity of all ROIs during the equivalent "first five" and "last five" time bins and found no significant change within either genotype (Fig. $4 f$ ).

We also analyzed the correlation between the WT and Fmr1 $\mathrm{KO}$ animals' proportions of time-locked neurons and the degree of their neuronal adaptation (adaptation index, see Materials and Methods) during the repeated stimulations. In WT mice, these two measures were significantly correlated (Spearman's $\rho=0.733$, $p=0.021$ by bootstrapping with 10,000 resamples; Fig. $4 g$ ). In Fmr1 KO mice, these two measures were not correlated (Spearman's $\rho=0.273, p=0.436$; Fig. $4 g$ ). This finding indicates that the defect in L2/3 neuronal adaptation in the Fmr1 KO mice is linked to their reduced proportion of time-locked neurons in local networks.

We next tested whether a similar lack of neuronal sensory adaptation was evident in adult Fmr1 KO mice, given that they show a clear avoidance response to repetitive whisker stimulation. We injected the AAV vector for GCaMP6s expression at 2-4 weeks before imaging and confirmed barrel cortex targeting using optical intrinsic signal imaging (see Materials and Methods). We did not find significant differences between adult WT and Fmr1 KO mice (P34-P74) in equivalent periods of spontaneous or whisker-evoked activity ( $p=1.00$ by two-group comparison; Fig. $5 a$ ). In contrast to P14-P16 mice, we did not find a difference in the proportion of time-locked L2/3 neurons between adult WT and Fmr1 KO mice ( $p=0.35$ by two-group comparison; Fig. $5 b$ ). However, whereas adult WT mice exhibited robust neuronal adaptation to repetitive whisker stimulation ( $Z$ scores, $2.42 \pm 0.53$ first five vs $1.58 \pm 0.53$ last five, $p=0.012$ by two-group comparison; Fig. 5c), adult Fmr1 KO animals did not (2.18 \pm 0.34 first five vs. $2.20 \pm 0.50$ last five, $p=1.000$; Fig. $5 c$ ).

In adult WT mice, both time-locked and non-time-locked cells showed adaptation ( $p=0.012$ and $p=0.066$; Fig. $5 d$ ), but adult Fmr1 KO mice did not show adaptation in either subset of cells $(p=0.258$ and $p=1.000$; Fig. $5 d)$. There was again no change in spontaneous activity of all ROIs between the equivalent "first five" and "last five" time bins (Fig. 5e). On the whole, the data in adult mice were similar to the results in P14-P16 mice.
The lack of modulation of the activity of non-time-locked cells in Fmr1 KO mice (especially at P14-P16) appears to be responsible for the overall network adaptation defect observed during repetitive whisker stimulation.

\section{Discussion}

A common symptom in FXS that is also seen in other ASDs is sensory hypersensitivity, frequently manifesting as tactile defensiveness (Liss et al., 2006; Sinclair et al., 2016). Sensory overreactivity is significant because it can contribute to other symptoms, such as anxiety, sleep disturbances, seizures, and inattention, and disrupt activities of daily living. Clinical interventions to improve sensory modulation in ASDs rely on behavioral or pharmacological treatments that are not specific for the underlying disorder (van Karnebeek et al., 2016). Coinciding with the disappointments of recent clinical trials aimed at molecular targets (Mullard, 2015), neuroscientists are increasingly turning to in vivo recordings of network activity in rodent models of ASDs (Gonçalves et al., 2013; Arnett et al., 2014; Zhang et al., 2014; Lu et al., 2016) to discover new therapeutic targets.

We followed such a symptom-to-circuit approach and designed our experiments to characterize circuit-level defects underlying sensory overreactivity in the Fmr1 KO mouse model of FXS. We first established a new behavioral assay for tactile defensiveness in young and adult mice, and then used in vivo calcium imaging with GCaMP6s to record ensemble activity of L2/3 neurons in the barrel cortex. Our main results are as follows: (1) P14-P16 Fmr1 KO mice demonstrate an exaggerated locomotor response during repetitive whisker stimulations. (2) Adult KO mice show an avoidance response to repetitive whisker stimulation, resembling tactile defensiveness in FXS patients. (3) Unexpectedly, we found no evidence of exaggerated sensory-evoked neuronal activity in $\mathrm{L} 2 / 3$ of young or adult $\mathrm{KO}$ mice. 4) The proportion of L2/3 neurons in barrel cortex that responds in a time locked manner to whisker stimulation is $45 \%$ lower in $\mathrm{KO}$ mice compared to WT mice at P14-P16. 5) Neuronal activity in both young and adult KO mice shows a lack of adaptation to repetitive whisker stimulation. Our results indicate that the absence of adaptation within local neuronal networks is a likely contributor to sensory overreactivity in FXS, and perhaps in other ASDs.

Active avoidance of tactile stimulation is challenging to study during early postnatal ages because of the small size and limited locomotion of neonatal mice. Although spontaneous whisker movements begin during the first postnatal week (Akhmetshina et al., 2016), mice do not show robust locomotion or true exploratory whisking before P13 (Arakawa and Erzurumlu, 2015; van der Bourg et al., 2016). Remarkably, our novel behavioral assay identified a behavioral equivalent of human tactile defensiveness: not only did we observe a pronounced increase in locomotion with repetitive whisker stimulation in $\mathrm{P} 14-\mathrm{P} 16$ Fmr1 KO mice (which we interpret as an escape behavior), but there was also a clear avoidance response (turning away from the aversive stimulus) in adult $\mathrm{KO}$ mice.

Considering that FXS symptoms present in the first year of life, we chose to carry out experiments during the second postnatal week, a critical age in mice analogous to an early perinatal period when sensory experience shapes somatosensory cortex in humans (Workman et al., 2013). The second postnatal week coincides with the onset of robust active whisking and with the consolidation of anatomical and functional "barrel" maps in the cortex (Petersen, 2007). Our results add to the notion that alterations in circuits during critical periods of experience-dependent plasticity are fundamental to the pathophysiology of FXS (Bu- 
a Spontaneous

(103 s)

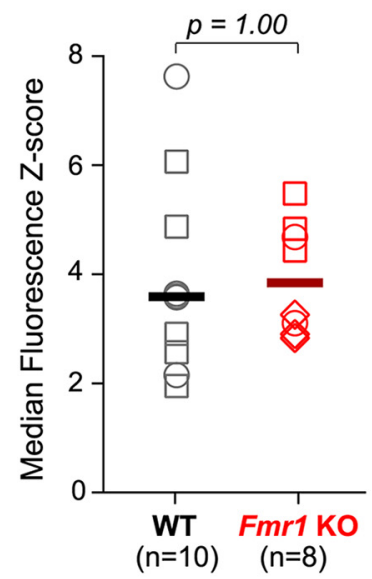

C

All ROls

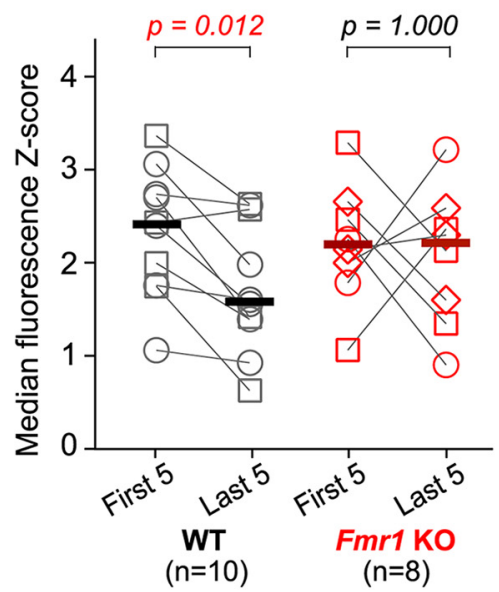

e Spontaneous activity, all ROls Equivalent time bins as Evoked

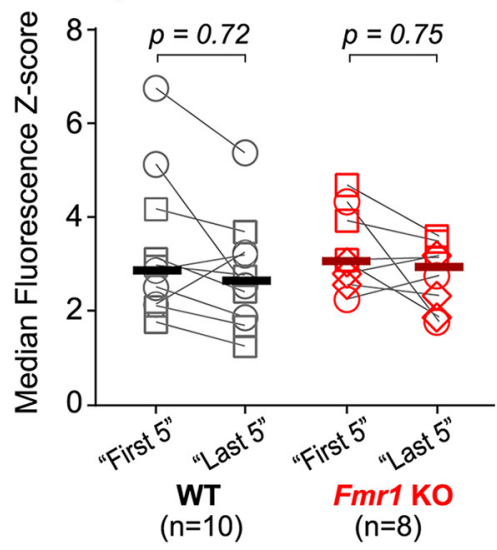

Evoked

(103 s, 20 stims)

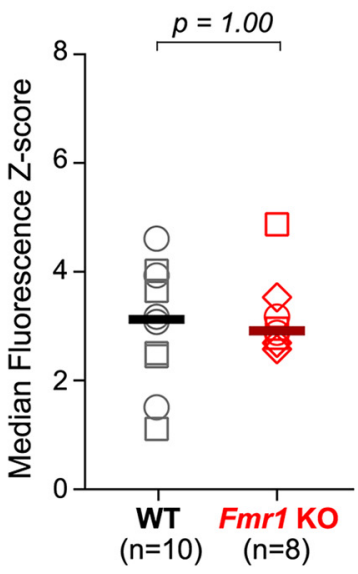

d Time-locked ROls
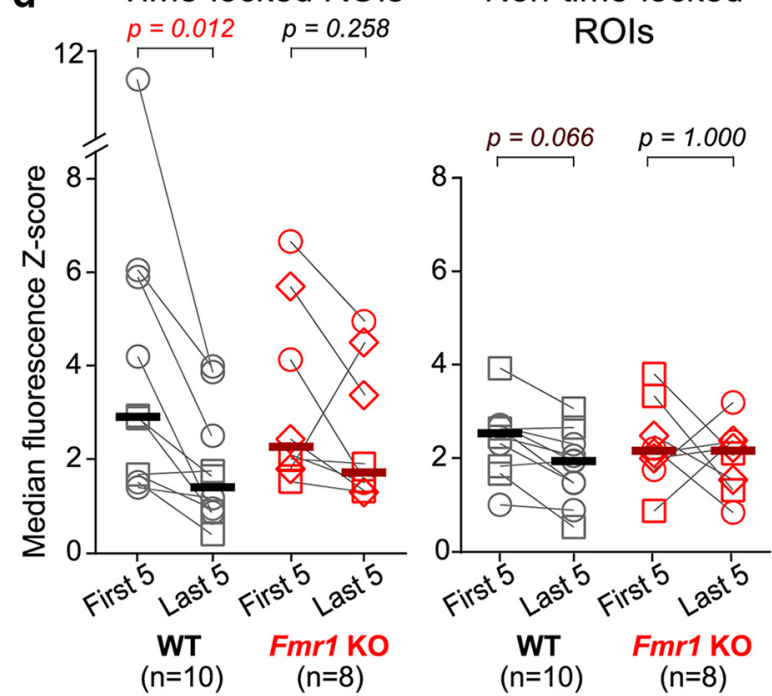

Non-time-locked ROls

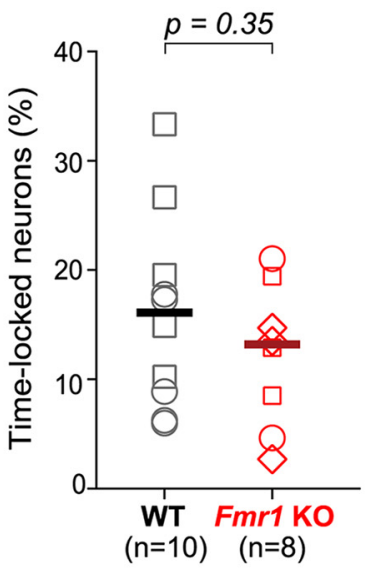


reau et al., 2008; Cruz-Martín et al., 2010; Harlow et al., 2010; Gonçalves et al., 2013; He et al., 2014) and ASDs in general (Meredith et al., 2012).

For our behavioral and calcium imaging experiments, we chose to stimulate groups of whiskers to better mimic the passive whole-snout inputs due to contact with littermates and grooming by the dam, which dominate the animals' early somatosensory experience. Our stimulation characteristics were also physiologically relevant, as exploratory whisking in mice is typically 5-15 $\mathrm{Hz}$ in 1-4 s bouts (Kleinfeld et al., 2006). Whereas each of our 20 stimulations $(10 \mathrm{~Hz}$ for $1 \mathrm{~s})$ was physiological in intensity and duration, the repetitive nature of the entire $80 \mathrm{~s}$ stimulation series was chosen to be more akin to a environmental stimulation that might be persistently irritating (e.g., wearing certain clothes) without being shocking (e.g., a brief but extremely loud sound). Our results on neuronal adaptation to repetitive whisker stimulation in early postnatal WT mice are consistent with those of a recent study using multielectrode array recordings (van der Bourg et al., 2016), in which barrel cortex activity in young mice was recorded during 10 consecutive 10-ms-long whisker deflections (200 ms ISI). It is important to note that the time course of stimulation and adaptation we chose is particularly relevant to studying the problem of tactile defensiveness in autism.

In adult mice, brief ( $200 \mathrm{~ms}$ ) deflections of two to three whiskers cause interwhisker inhibition between barrel cortex neurons within <500 ms (Simons, 1985). Conversely, during $10 \mathrm{~Hz}$ multiwhisker stimulations lasting $1 \mathrm{~s}$, adaptation of barrel cortex neurons enables surround facilitation instead of suppression (Ramirez et al., 2014). As we examined adaptation over much longer time scales, it is unlikely that single-whisker stimulation would reveal different results. [We find that single-whisker stimulation also leads to neuronal adaptation in WT mice (data not shown)]. One caveat regarding the interpretation of our results is that we imaged L2/3 activity in barrel cortex of lightly sedated mice, to maintain a consistent behavioral state, as well as to minimize active whisking events that might contribute to feedbackenhanced cortical activity and contaminate our recordings (Petersen, 2007). While deep anesthesia ( $>1 \%$ isoflurane) is known to produce a markedly different neuronal activity pattern from the awake state, light $(<0.5 \%)$ isoflurane allows a sparse, desynchronized pattern of neuronal population activity that is similar to the awake state (Lissek et al., 2016).

We unexpectedly found that the proportion of $\mathrm{L} 2 / 3$ neurons showing time-locked responses to whisker stimulation was much lower in Fmr1 KO than in WT animals at P14-P16 (though not evident in adult mice), and that sensory stimulation did not trigger abnormally high activity in neurons from $\mathrm{KO}$ mice at either age. This seems to contradict predictions of the theory of neuronal and network hyperexcitability in FXS (Contractor et al., 2015). However, the L $2 / 3$ activity from single-whisker stimulation is distributed across several cortical columns, with only $25 \%$ of excitatory neurons in a single imaging field showing responses tuned to the anatomically associated whisker (Clancy et al., 2015). It is possible that in $\mathrm{KO}$ mice the functional circuits for whisker touch processing are dispersed over an even larger spatial area, resulting in an apparently reduced proportion of time-locked neurons within any given local network (about $200 \mu \mathrm{m}$ in diameter), as we observed. Indeed, recent studies using OIS and in vivo electrophysiology found that single-whisker stimulation resulted in a larger spatial area of activation across the Fmr1 KO barrel cortex, compared with WT (Arnett et al., 2014; Juczewski et al., 2016).

Adaptation of cortical neurons to repeated or ongoing sensory stimulation is a robust phenomenon across sensory modalities, enabling increased detection and discriminability (Castro-Alamancos, 2004; Ollerenshaw et al., 2014). Given our results, Fmr1 KO mice would be expected to show impairments in behavioral tasks that assess tactile perception and perceptual decision making. Indeed, these mice have demonstrated impaired texture discrimination during novel object recognition (Orefice et al., 2016), as well as reduced whisker sampling (Juczewski et al., 2016) and impaired learning (Arnett et al., 2014) in the gap-crossing assay.

The neuronal adaptation defect we observed in Fmr1 KO L2/3 cortical neurons could also reflect upstream changes in sensory neurons in the periphery, brainstem, thalamus, or even in L4 neurons of barrel cortex. For example, a recent study identified hyperexcitability in peripheral somatosensory neurons of several mouse models of ASDs (Orefice et al., 2016), and the same defects could be present in Fmr1 KO mice. Previous studies in the Fmr1 KO somatosensory cortex have identified specific functional defects in thalamocortical synapses during both development (Harlow et al., 2010) and adulthood (Gibson et al., 2008), as well as defects in transmission and experience-dependent plasticity in L4-to-L3 projections (Bureau et al., 2008). More work is needed to establish whether a loss of adaptation originates in the periphery and spreads to somatosensory cortex, or whether it occurs simultaneously throughout the brain.

Our findings raise additional questions about the role of downstream brain regions in translating a lack of neuronal adaptation in somatosensory cortex into an avoidance/escape response to an aversive sensory stimulus. Altered sensory adaptation in Fmrl $\mathrm{KO}$ circuits could also involve infragranular output layers (L5/6) in barrel cortex. However, in early postnatal WT mice, L5 and L6 neurons tend to show facilitation (i.e., an increase in activity, not decrease) to repetitive whisker stimulation (van der Bourg et al., 2016). Beyond the cortex, the amygdala is almost certainly involved in sensory overreactivity in ASDs (Green et al., 2013, 2015), and outputs of the basal ganglia were shown recently to modulate active avoidance (Hormigo et al., 2016). Future studies should address how specific relevant brain regions, pathways, and neurotransmitters are involved in top-down modulation of tactile defensiveness, and we have shown that Fmrl $\mathrm{KO}$ mice are an ideal model in which to study these questions.

We speculate that altered sensory processing in the cortex might lead to anxiety and hyperarousal and ultimately contribute to the observed defensiveness behavior in Fmr1 KO mice. Our data fit well with not just the known behavioral phenotypes of KO mice and FXS patients, but also with existing EEG studies on sensory adaptation defects in $\mathrm{KO}$ mice and humans (Castrén et al., 2003; Van der Molen et al., 2012; Ethridge et al., 2016; Lovelace et al., 2016; Sinclair et al., 2016). A previous fMRI study also found a defect in adaptation to repeated tactile stimulus in the somatosensory cortex of patients (age 9-17) with both ASD and documented sensory overreactivity (Green et al., 2015). Our work encourages additional investigations using animal models of ASD at developmental stages to elucidate neuronal defects underlying aberrant behaviors that are relevant to human symptoms and function.

\section{References}

Akhmetshina D, Nasretdinov A, Zakharov A, Valeeva G, Khazipov R (2016) The nature of the sensory input to the neonatal rat barrel cortex. J Neurosci 36:9922-9932. CrossRef Medline

Arakawa H, Erzurumlu RS (2015) Role of whiskers in sensorimotor development of C57BL/6 mice. Behav Brain Res 287:146-155. CrossRef Medline

Arnett MT, Herman DH, McGee AW (2014) Deficits in tactile learning in a mouse model of fragile X syndrome. PLoS One 9:e109116. CrossRef Medline 
Belmonte MK, Allen G, Beckel-Mitchener A, Boulanger LM, Carper RA, Webb SJ (2004) Autism and abnormal development of brain connectivity. J Neurosci 24:9228-9231. CrossRef Medline

Ben-Sasson A, Cermak SA, Orsmond GI, Tager-Flusberg H, Carter AS, Kadlec MB, Dunn W (2007) Extreme sensory modulation behaviours in toddlers with autism spectrum disorder. Am J Occup Ther 61:584-592. CrossRef Medline

Bernardet M, Crusio WE (2006) Fmrl KO mice as a possible model of autistic features. Sci World J 6:1164-1176. CrossRef

Bureau I, Shepherd GM, Svoboda K (2008) Circuit and plasticity defects in the developing somatosensory cortex of FMR1 knock-out mice. J Neurosci 28:5178-5188. CrossRef Medline

Butler MG, Mangrum T, Gupta R, Singh DN (1991) A 15-item checklist for screening mentally retarded males for the fragile X syndrome. Clin Genet 39:347-354. Medline

Castrén M, Pääkkönen A, Tarkka IM, Ryynänen M, Partanen J (2003) Augmentation of auditory N1 in children with fragile X syndrome. Brain Topogr 15:165-171. CrossRef Medline

Castro-Alamancos MA (2004) Absence of rapid sensory adaptation in neocortex during information processing states. Neuron 41:455-464. CrossRef Medline

Chen TW, Wardill TJ, Sun Y, Pulver SR, Renninger SL, Baohan A, Schreiter ER, Kerr RA, Orger MB, Jayaraman V, Looger LL, Svoboda K, Kim DS (2013) Ultrasensitive fluorescent proteins for imaging neuronal activity. Nature 499:295-300. CrossRef Medline

Clancy KB, Schnepel P, Rao AT, Feldman DE (2015) Structure of a single whisker representation in layer 2 of mouse somatosensory cortex. J Neurosci 35:3946-3958. CrossRef Medline

Contractor A, Klyachko VA, Portera-Cailliau C (2015) Altered neuronal and circuit excitability in fragile X syndrome. Neuron 87:699-715. CrossRef Medline

Cruz-Martín A, Crespo M, Portera-Cailliau C (2010) Delayed stabilization of dendritic spines in fragile X mice. J Neurosci 30:7793-7803. CrossRef Medline

Dombeck DA, Khabbaz AN, Collman F, Adelman TL, Tank DW (2007) Imaging large-scale neural activity with cellular resolution in awake, mobile mice. Neuron 56:43-57. CrossRef Medline

Ethridge LE, White SP, Mosconi MW, Wang J, Byerly MJ, Sweeney JA (2016) Reduced habituation of auditory evoked potentials indicate cortical hyperexcitability in fragile X syndrome. Transl Psychiatry 6:e787. CrossRef Medline

Frye CG, MacLean JN (2016) Spontaneous activations follow a common developmental course across primary sensory areas in mouse neocortex. J Neurophysiol 116:431-437. Medline

Gibson JR, Bartley AF, Hays SA, Huber KM (2008) Imbalance of neocortical excitation and inhibition and altered UP states reflect network hyperexcitability in the mouse model of fragile X syndrome. J Neurophysiol 100: 2615-2626. CrossRef Medline

Golshani P, Gonçalves JT, Khoshkhoo S, Mostany R, Smirnakis S, PorteraCailliau C (2009) Internally mediated developmental desynchronization of neocortical network activity. J Neurosci 29:10890-10899. CrossRef Medline

Gonçalves JT, Anstey JE, Golshani P, Portera-Cailliau C (2013) Circuit level defects in the developing neocortex of fragile X mice. Nat Neurosci 16: 903-909. CrossRef Medline

Grant RA, Mitchinson B, Prescott TJ (2012) The development of whisker control in rats in relation to locomotion. Dev Psychobiol 54:151-168. CrossRef Medline

Green SA, Rudie JD, Colich NL, Wood JJ, Shirinyan D, Hernandez L, Tottenham N, Dapretto M, Bookheimer SY (2013) Overreactive brain responses to sensory stimuli in youth with autism spectrum disorders. J Am Acad Child Adolesc Psychiatry 52:1158-1172. CrossRef Medline

Green SA, Hernandez L, Tottenham N, Krasileva K, Bookheimer SY, Dapretto M (2015) Neurobiology of sensory overresponsivity in youth with autism spectrum disorders. JAMA Psychiatry 72:778-786. CrossRef Medline

Hagerman RJ, Amiri K, Cronister A (1991) Fragile X checklist. Am J Med Genet 38:283-287. CrossRef Medline

Harlow EG, Till SM, Russell TA, Wijetunge LS, Kind P, Contractor A (2010) Critical period plasticity is disrupted in the barrel cortex of Fmr1 knockout mice. Neuron 65:385-398. CrossRef Medline

He Q, Nomura T, Xu J, Contractor A (2014) The developmental switch in
GABA polarity is delayed in fragile X mice. J Neurosci 34:446-450. CrossRef Medline

Heiss JE, Katz Y, Ganmor E, Lampl I (2008) Shift in the balance between excitation and inhibition during sensory adaptation of S1 neurons. J Neurosci 28:13320-13330. CrossRef Medline

Hormigo S, Vega-Flores G, Castro-Alamancos MA (2016) Basal ganglia output controls active avoidance behavior. J Neurosci 36:10274-10284. CrossRef Medline

Johnston DG, Denizet M, Mostany R, Portera-Cailliau C (2013) Chronic in vivo imaging shows no evidence of dendritic plasticity or functional remapping in the contralesional cortex after stroke. Cereb Cortex 23:751762. CrossRef Medline

Juczewski K, von Richthofen H, Bagni C, Celikel T, Fisone G, Krieger P (2016) Somatosensory map expansion and altered processing of tactile inputs in a mouse model of fragile X syndrome. Neurobiol Dis 96:201215. CrossRef Medline

Kerr JN, de Kock CP, Greenberg DS, Bruno RM, Sakmann B, Helmchen F (2007) Spatial organization of neuronal population responses in layer 2/3 of rat barrel cortex. J Neurosci 27:13316-13328. CrossRef Medline

Kleinfeld D, Ahissar E, Diamond ME (2006) Active sensation: insights from the rodent vibrissa sensorimotor system. Curr Opin Neurobiol 16:435444. CrossRef Medline

Liss M, Saulnier C, Fein D, Kinsbourne M (2006) Sensory and attention abnormalities in autistic spectrum disorders. Autism 10:155-172. CrossRef Medline

Lissek T, Obenhaus HA, Ditzel DAW, Nagai T, Miyawaki A, Sprengel R, Hasan MT (2016) General anesthetic conditions induce network synchrony and disrupt sensory processing in the cortex. Front Cell Neurosci 10:64. Medline

Lovelace JW, Wen TH, Reinhard S, Hsu MS, Sidhu H, Ethell IM, Binder DK, Razak KA (2016) Matrix metalloproteinase-9 deletion rescues auditory evoked potential habituation deficit in a mouse model of fragile X syndrome. Neurobiol Dis 89:126-135. CrossRef Medline

Lu H, Ash RT, He L, Kee SE, Wang W, Yu D, Hao S, Meng X, Ure K, Ito-Ishida A, Tang B, Sun Y, Ji D, Tang J, Arenkiel BR, Smirnakis SM, Zoghbi HY (2016) Loss and gain of MeCP2 cause similar hippocampal circuit dysfunction that is rescued by deep brain stimulation in a Rett syndrome mouse model. Neuron 91:739-747. CrossRef Medline

Marco EJ, Hinkley LB, Hill SS, Nagarajan S (2011) Sensory processing in autism: a review of neuropsychologic findings. Pediatr Res 69:48R-54R. Medline

Mégevand P, Troncoso E, Quairiaux C, Muller D, Michel CM, Kiss JZ (2009) Long-term plasticity in mouse sensorimotor circuits after rhythmic whisker stimulation. J Neurosci 29:5326-5335. CrossRef Medline

Meredith RM, Dawitz J, Kramvis I (2012) Sensitive time-windows for susceptibility in neurodevelopmental disorders. Trends Neurosci 35:335344. CrossRef Medline

Mineault PJ, Tring E, Trachtenberg JT, Ringach DL (2016) Enhanced spatial resolution during locomotion and heightened attention in mouse primary visual cortex. J Neurosci 36:6382-6392. CrossRef Medline

Mostany R, Portera-Cailliau C (2008) A craniotomy surgery procedure for chronic brain imaging. J Vis Exp 12:e680. Medline

Mullard A (2015) Fragile X disappointments upset autism ambitions. Nat Rev Drug Discov 14:151-153. CrossRef Medline

Niell CM, Stryker MP (2010) Modulation of visual responses by behavioral state in mouse visual cortex. Neuron 65:472-479. CrossRef Medline

O’Donnell C, Gonçalves JT, Whiteley N, Portera-Cailliau C, Sejnowski T) (2017) The population tracking model: a simple, scalable statistical model for neural population data. Neural Comput 29:50-93. CrossRef Medline

Ollerenshaw DR, Zheng HJ, Millard DC, Wang Q, Stanley GB (2014) The adaptive trade-off between detection and discrimination in cortical representations and behavior. Neuron 81:1152-1164. CrossRef Medline

Orefice LL, Zimmerman AL, Chirila AM, Sleboda SJ, Head JP, Ginty DD (2016) Peripheral mechanosensory neuron dysfunction underlies tactile and behavioral deficits in mouse models of ASDs. Cell 166:299-313. CrossRef Medline

Petersen CC (2007) The functional organization of the barrel cortex. Neuron 56:339-355. CrossRef Medline

Pologruto TA, Sabatini BL, Svoboda K (2003) ScanImage: flexible software for operating laser scanning microscopes. Biomed Eng Online 2:13. CrossRef Medline 
Ramirez A, Pnevmatikakis EA, Merel J, Paninski L, Miller KD, Bruno RM (2014) Spatiotemporal receptive fields of barrel cortex revealed by reverse correlation of synaptic input. Nat Neurosci 17:866-875. CrossRef Medline

Reddy KS (2005) Cytogenetic abnormalities and fragile-x syndrome in autism spectrum disorder. BMC Med Genet 6:3. Medline

Rochefort NL, Garaschuk O, Milos RI, Narushima M, Marandi N, Pichler B, Kovalchuk Y, Konnerth A (2009) Sparsification of neuronal activity in the visual cortex at eye-opening. Proc Natl Acad Sci U S A 106:1504915054. CrossRef Medline

Simons DJ (1985) Temporal and spatial integration in the rat SI vibrissa cortex. J Neurophysiol 54:615-635. Medline

Sinclair D, Oranje B, Razak KA, Siegel SJ, Schmid S (2016) Sensory processing in autism spectrum disorders and fragile $\mathrm{X}$ syndrome-from the clinic to animal models. Neurosci Biobehav Rev 76:235-253. Medline

The Dutch-Belgian Fragile X Consortium (1994) Fmr1 knockout mice: a model to study fragile $\mathrm{X}$ mental retardation. Cell 78:23-33. Medline

van der Bourg A, Yang JW, Reyes-Puerta V, Laurenczy B, Wieckhorst M, Stüttgen MC, Luhmann HJ, Helmchen F (2016) Layer-specific refine- ment of sensory coding in developing mouse barrel cortex. Cereb Cortex, in press. Medline

Van der Molen MJ, Van der Molen MW, Ridderinkhof KR, Hamel BC, Curfs LM, Ramakers GJ (2012) Auditory change detection in fragile X syndrome males: a brain potential study. Clin Neurophysiol 123:1309-1318. CrossRef Medline

van Karnebeek CD, Bowden K, Berry-Kravis E (2016) Treatment of neurogenetic developmental conditions: from 2016 into the future. Pediatr Neurol 65:1-13. CrossRef Medline

Wassink TH, Piven J, Patil SR (2001) Chromosomal abnormalities in a clinic sample of individuals with autistic disorder. Psychiatr Genet 11:5763. CrossRef Medline

Workman AD, Charvet CJ, Clancy B, Darlington RB, Finlay BL (2013) Modeling transformations of neurodevelopmental sequences across mammalian species. J Neurosci 33:7368-7383. CrossRef Medline

Zhang Y, Bonnan A, Bony G, Ferezou I, Pietropaolo S, Ginger M, Sans N, Rossier J, Oostra B, LeMasson G, Frick A (2014) Dendritic channelopathies contribute to neocortical and sensory hyperexcitability in Fmr 1(-/y) mice. Nat Neurosci 17:1701-1709. CrossRef Medline 